\title{
Capacity Choice in a Price-Setting Mixed Duopoly: The Relative Performance Approach ${ }^{*}$
}

\author{
Yasuhiko Nakamura ${ }^{1}$, Masayuki Saito ${ }^{2}$ \\ ${ }^{1}$ College of Economics, Nihon University, Tokyo, Japan \\ ${ }^{2}$ Faculty of Economics and Business Administration, Reitaku University, Chiba, Japan \\ Email: yasuhiko.r.nakamura@gmail.com
}

Received February 14, 2013; revised March 20, 2013; accepted April 12, 2013

Copyright (C) 2013 Yasuhiko Nakamura, Masayuki Saito. This is an open access article distributed under the Creative Commons Attribution License, which permits unrestricted use, distribution, and reproduction in any medium, provided the original work is properly cited.

\begin{abstract}
This paper analyzes the capacity choice issue under a price-setting mixed duopoly with differentiated goods, when the objective function of the private firm is its relative profit. In this paper, we show that the public firm chooses over-capacity irrespective of the degree of product differentiation and the degree of importance of the relative performance of the private firm. In contrast, we find that the difference between the output and capacity levels of the private firm strictly depends on both the degree of product differentiation and the degree of importance of its relative performance. More precisely, the private firm chooses over-capacity when the degree of importance of its relative performance is high relative to the degree of product differentiation, whereas it chooses under-capacity otherwise.
\end{abstract}

Keywords: Mixed Duopoly; Relative Profit; Price Competition

\section{Introduction}

This paper reconsiders the capacity choices of a public firm that is a welfare-maximizer and a private firm that is a relative-profit-maximizer in the context of a price-setting mixed duopoly. More precisely, in this paper, taking into account that the objective function of the private firm is its relative profit, we consider the impact of the degree of importance of its relative performance on the difference between their output and their capacity levels of both the public firm and the private firm in a pricesetting mixed duopoly. The main contribution of this paper is that given the degree of product differentiation, it is shown that the difference between the output level and capacity levels of the private firm changes with the degree of importance of its relative performance.

Nishimori and Ogawa [1] considered the capacity choice problem à la Horiba and Tsutsui [2] in a mixed duopolistic market with homogeneous goods ${ }^{1}$. Nishimori and Ogawa [1] showed that the public firm strategically

\footnotetext{
"Nakamura thanks the financial support by KAKENHI (23730226). All remaining errors are our own.

${ }^{1}$ In a private oligopolistic setting, the capacity choice of each firm has been comprehensively investigated since Dixit [3], Brander and Spencer [4], and so on. In contrast, there exists Wen and Sasaki [5] as an example of the literature belonging to another strand of capacity choice in a mixed oligopoly.
}

chooses under-capacity, whereas the private firm chooses over-capacity, which is in striking contrast to the result obtained in a private oligopoly. Subsequently, Ogawa [6] and Bárcena-Ruiz and Garzón [7] extended the model in Nishimori and Ogawa [1] to include product differentiation in a quantity-setting competition and a price-setting competition, respectively ${ }^{2}$. This paper extends the model in Bárcena-Ruiz and Garzón [7] by introducing the degree of importance of the private firm's relative performance. The main purpose of this paper is to check the robustness of the results to the difference between the output and capacity levels of both the public firm and the private firm, which was obtained in Bárcena-Ruiz and Garzón [7].

In this paper, we show that under the assumption that the products of the public firm and the private firm are restricted to being substitutable, the public firm sets over-

\footnotetext{
${ }^{2}$ More recently, in capacity choice in a mixed oligopoly, $\mathrm{Lu}$ and Poddar [8] and $\mathrm{Lu}$ and Poddar [9] analyzed the case of each firm's sequential move and the case of demand uncertainty, respectively. Subsequently, Tomaru et al. [10] introduced the separation between ownership and management in the fashion of Fershtman and Judd [11], Sklivas [12], and Vickers [13] into in the models of Ogawa [6] and Bárcena-Ruiz and Garzón [7]. Most recently, Lu and Poddar [14] and Bárcena-Ruiz and Garzón [15] investigated each firm's endogenous timing games on capacity choices in a quantity-setting mixed duopoly and a price-setting mixed duopoly with differentiated goods, respectively.
} 
capacity for any value of the degree of importance of the private firm's relative performance. The intuition behind this result is given by the same logic as that presented in Bárcena-Ruiz and Garzón [7]. In a price-setting mixed duopoly, as long as the relation between the goods of the public firm and the private firm is substitutable, the price level of the private firm is negatively associated with the capacity level of the public firm for any value of the degree of importance of the private firm's relative performance, and thus the output level of the private firm is positively associated with the capacity level of the public firm for any value of the degree of importance of the private firm's relative performance. Hence, the public firm attempts to enhance the social welfare through inducing the aggressive behavior of the private firm by setting a relatively high capacity level; consequently, the public firm sets over-capacity for any value of the degree of importance of the private firm's relative performance, when the relation between the goods of both the firms is substitutable.

In contrast, in this paper, we find that the private firm chooses over-capacity when the degree of importance of its relative performance is highly relative to the degree of product differentiation, whereas the private firm chooses under-capacity otherwise. When the degree of importance of the private firm's relative performance is high relative to the degree of product differentiation, the private firm aggressively behaves in the market in the case wherein it is a relative-profit-maximizer rather than in the case wherein it is only a profit-maximizer, implying its relatively low price level and its high output level. Consequently, although the goods of both firms are restricted to being substitutable, we show that the difference between the output and capacity levels of the private firm changes in accordance with the degree of importance of its relative performance and the degree of product differentiation. Therefore, in the context of the capacity choice in a mixed duopoly, whether the private firm chooses over-capacity or under-capacity depends not only on its strategic variable and the degree of product differentiation but also on the degree of importance of its relative performance.

The remainder of this paper is organized as follows. In Section 2, we formulate a price-setting mixed duopolistic model with the capacity choices of both the public firm and the private firm. In Section 3, we consider the difference between the output and capacity levels of both the firms using the model built in Section 2. Section 4 concludes with several remarks. Each firm's equilibrium price level is relegated to the Appendix ${ }^{3}$.

\section{The Model of a Price Competition in a Mixed Duopoly}

We formulate a price-setting mixed duopolistic model where both the public firm (firm 0) and the private firm (firm 1) can choose not only their prices but also their capacities. The basic structure of the model follows a standard product differentiation model as in Singh and Vives [16]. Each firm produces a differentiated good. A representative consumer's utility $U$ is give as

$$
U\left(q_{0}, q_{1} ; q\right)=a\left(q_{0}+q_{1}\right)-\frac{q_{0}^{2}+2 b q_{0} q_{1}+q_{1}^{2}}{2}+q .
$$

where $a>0, b \in(0,1)$ represents the degree of product differentiation, and $q$ represents the numeraire good ${ }^{4}$. The above specification implies the following demand function: for the positive prices of both the firms,

$$
q_{i}=\left[a(1-b)-p_{i}+b p_{j}\right] /\left(1-b^{2}\right), \quad i, j=1,2 ; i \neq j .
$$

We suppose that both firms adopt identical technologies represented by the cost function $C_{i}\left(q_{i}, x_{i}\right)$, where $x_{i}$ is the capacity level of firm $i, \quad(i=0,1)$. Following Vives [17], Ogawa [6], Bárcena-Ruiz and Garzón [7], and Tomaru et al. [10], we assume that the cost function is given by $C_{i}\left(q_{i}, x_{i}\right)=m q_{i}+\left(q_{i}-x_{i}\right)^{2}, \quad(i=0,1)^{5}$. This cost function implies that if each firm's output level equals its capacity level, i.e., $q_{i}=x_{i}$, then the long-run average cost is minimized. The profit of firm $i$ is given by $\Pi_{i}=p_{i} q_{i}-C_{i}\left(q_{i}, x_{i}\right),(i=0,1)$. Consumer surplus as the representative consumer utility is represented as follows:

$$
C S=U\left(q_{0}, q_{1}\right)-p_{0} q_{0}-p_{1} q_{1}=\left[2 a^{2}(1-b)+p_{0}^{2}-2 b p_{0} p_{1}+p_{1}^{2}-2 a(1-b)\left(p_{0}+p_{1}\right)\right] /\left[2\left(1-b^{2}\right)\right]+q
$$

whereas producer surplus is given by the sum of the

\footnotetext{
${ }^{3}$ The equilibrium market outcomes including each firm's profit, consumer surplus, and social welfare are available upon request.

${ }^{4}$ Throughout this paper, we restrict the parameter $b$ to $(0,1)$ in order to ensure the nonnegativity of all equilibrium market outcomes. $b \in(0,1)$ implies that the goods produced by both firms are substitutable. In particular, when the goods are complementary, $b \in(-1,0)$, the equilibrium profit of the public firm may become negative.
}

of both firms, $\Pi_{0}+\Pi_{1}$.

Let $V_{i}=\Pi_{i}-\beta \Pi_{j}$ be firm $i$ 's relative profit $(i, j=0,1 ; i \neq j)$. Then, the payoff of firm 1 is given by $V_{1}$, whereas the payoff of firm 0 is given by $W$, where $W$ is the total social surplus (the sum of consumer surplus

\footnotetext{
${ }^{5}$ We assume that $\alpha>m$ in order to ensure the nonnegativity of all equilibrium outcomes.
} 
and producer surplus) ${ }^{6}$. Moreover, we assume that $\beta \in[0,1)^{7}$. Parameter $\beta$ indicates the degree of the importance of the relative performance of the private firm 1 .

We investigate the game with the following orders of each firm's move. In the first stage, firms 0 and 1 simultaneously set their capacity levels. In the second stage, after both firms observe each other's capacity level, they engage in a price-setting competition.

\section{Equilibrium Analysis and the Results}

We solve the game by backward induction from the second stage to obtain a subgame perfect Nash equilibrium. In the second stage, firm 0 maximizes social welfare $W$ with respect to $p_{0}$, whereas firm 1 maximizes its payoff $V_{1}$ with respect to $p_{1}$. The first-order conditions of firms 0 and 1 are, respectively, given as

$$
\begin{gathered}
\frac{\partial W}{\partial p_{0}}=\frac{2 a(1-b)^{2}+(1-b)^{2}(1+b) m-3 p_{0}-b^{2} p_{0}+5 b p_{1}-b^{3} p_{1}-2 x_{0}+2 b^{2} x_{0}+2 b x_{1}-2 b^{3} x_{1}}{\left(1-b^{2}\right)^{2}}=0 \\
\Leftrightarrow p_{0}=\frac{2 a(1-b)^{2}+(1-b)^{2}(1+b) m+5 b p_{1}-b^{3} p_{1}-2 x_{0}+2 b^{2} x_{0}+2 b x_{1}-2 b^{3} x_{1}}{3+b^{2}}, \\
=\frac{\partial V_{1}}{\partial p_{1}} \\
=\frac{3 b p_{0}-b^{3} p_{0}-4 p_{1}+2 b^{2} p_{1}-2 x_{1}+2 b^{2} x_{1}-3 b p_{0} \beta+b^{3} p_{0} \beta+2 b^{2} p_{1} \beta-2 b x_{0} \beta+2 b^{3} x_{0} \beta+a(1-b)\left(3-b^{2}+2 b \beta\right)+\left(1-b^{2}\right) m(1+b \beta)}{\left(1-b^{2}\right)^{2}}=0 \\
\Leftrightarrow p_{1}=\frac{a(1-b)\left(3-b^{2}+2 b \beta\right)+\left(1-b^{2}\right) m(1+b \beta)+3 b p_{0}-b^{3} p_{0}-2 x_{1}+2 b^{2} x_{1}-3 b p_{0} \beta+b^{3} p_{0} \beta-2 b x_{0} \beta+2 b^{2} x_{0} \beta}{2\left[2-b^{2}(1+\beta)\right]}
\end{gathered}
$$

yielding

$$
=\frac{a\left[8-b+b^{4}-b^{2}(3-6 \beta)-b^{3}(1+2 \beta)\right]+(1+b) m\left[4-3 b-b^{3} \beta+b^{2}(1+3 \beta)\right]-8 x_{0}+4 b^{2} x_{0}-2 b x_{1}-2 b^{3} x_{1}-6 b^{2} x_{0} \beta+2 b^{4} x_{0} \beta-4 b^{3} x_{1} \beta}{12-b^{2}(5-9 \beta)+b^{4}(1-\beta)},
$$

$$
=\frac{a(3-b)\left[3-b^{2}(1-2 \beta)\right]+(1+b) m\left[3-b^{2}(2-3 \beta)+b^{3}(1-\beta)\right]-6 b x_{0}+2 b^{3} x_{0}-6 x_{1}+4 b^{2} x_{1}-2 b^{4} x_{1}-4 b^{3} x_{0} \beta-6 b^{2} x_{1} \beta+2 b^{4} x_{1} \beta}{12-b^{2}(5-9 \beta)+b^{4}(1-\beta)} \text {. }
$$

In the first stage, both firms know that their capacity choices affect their price levels in the second stage. Given Equations (1) and (2), firms 0 and 1 simultaneously and independently set their capacity levels with respect to social welfare and the relative profit of private firm 1, respectively. Thus, by solving the first-order conditions of firms 0 and 1 in the first stage, we have

$$
\begin{aligned}
& x_{0}=\frac{(a-m)\left[48-3 b(5-\beta)-3 b^{2}(1-\beta)^{2}+b^{3}(1-\beta)^{2}\right]-2 b x_{1}\left[3(5-\beta)-b^{2}(1-\beta)^{2}\right]}{48+b^{4}(1-\beta)^{2}-6 b^{2}(1-\beta)(3+\beta)}, \\
& x_{1}=\frac{(a-m)\left[36+4 b^{2} \beta-b^{3}(1-\beta) \beta-4 b(3-2 \beta)\right]-2 b x_{0}\left[12-\left(8-b^{2}\right) \beta-b^{2} \beta^{2}\right]}{72+b^{4}(1-\beta)^{2}-8 b^{2}(3-2 \beta)},
\end{aligned}
$$

\footnotetext{
${ }^{6}$ Similar to Matsumura and Okamura [18] and Nakamura and Saito [19], we regard social welfare as the sum of consumer surplus and the profits of firms 0 and 1 rather than the sum of consumer surplus and the relative profits of firms 0 and 1 . Although firms' CEOs emphasize relative profit rather than original profit because their relatively good performance increases the current and future income, we consider this to mean an income transfer. This is why we suppose that social welfare in this paper is equal to the sum of consumer surplus and producer surplus.

${ }^{7}$ As indicated in Matsumura and Matsushima [20] and Nakamura and Saito [19], if we adopt the sales delegation approach as in Fershtman and Judd [11], Sklivas [12], and Vickers [13] and replace each firm's sales with the (negative) profit of the opponent firm in their model, the firms would use a positive value of $\beta$. Moreover, see the works of Kockesen et al. [21] and Joe [22] for detailed discussions on arguments and empirical results presenting views supporting both positive and negative values of $\beta$.
} 
yielding

$$
\begin{gathered}
{\left[288-180 b-b^{2}(396-606 \beta)+b^{11}(1-\beta)^{3}+3 b^{3}(65-141 \beta)+b^{4}\left(295-537 \beta+460 \beta^{2}\right)\right.} \\
-b^{5}\left(113-345 \beta+324 \beta^{2}\right)-b^{6}\left(112-274 \beta+233 \beta^{2}-125 \beta^{3}\right)-b^{9}\left(9-33 \beta+42 \beta^{2}-18 \beta^{3}\right) \\
x_{0}^{*}=(a-m) \frac{\left.-b^{10}\left(2-6 \beta+5 \beta^{2}-\beta^{3}\right)+3 b^{7}\left(14-48 \beta+57 \beta^{2}-27 \beta^{3}\right)+b^{8}\left(23-61 \beta+66 \beta^{2}-30 \beta^{3}\right)\right]}{\left[288-b^{2}(576-636 \beta)+b^{12}(1-\beta)^{3}+b^{4}\left(490-950 \beta+568 \beta^{2}\right)-b^{6}\left(225-607 \beta+569 \beta^{2}-239 \beta^{3}\right)\right.}, \\
\left.+b^{8}\left(65-199 \beta+237 \beta^{2}-135 \beta^{3}+36 \beta^{4}\right)-b^{10}\left(11-37 \beta+47 \beta^{2}-25 \beta^{3}+4 \beta^{4}\right)\right] \\
{\left[144-48 b(3-\beta)-b^{11}(1-\beta)^{2} \beta+2 b^{10}(1-\beta)^{2} \beta(1+\beta)-66 b^{2}(2-5 \beta)+b^{4}\left(42-278 \beta+202 \beta^{2}\right)\right.} \\
+4 b^{3}\left(33-83 \beta+42 \beta^{2}\right)-b^{5}\left(42-251 \beta+284 \beta^{2}-171 \beta^{3}\right)-2 b^{6}\left(3-46 \beta+67 \beta^{2}-\beta^{3}\right) \\
x_{1}^{*}=(a-m) \frac{\left.-6 b^{8} \beta\left(3-5 \beta+3 \beta^{3}\right)+b^{9} \beta\left(13-28 \beta+21 \beta^{2}-6 \beta^{3}\right)+b^{7}\left(6-75 \beta+142 \beta^{2}-95 \beta^{3}+54 \beta^{4}\right)\right]}{\left[288-b^{2}(576-636 \beta)+b^{12}(1-\beta)^{3}+b^{4}\left(490-950 \beta+568 \beta^{2}\right)-b^{6}\left(225-607 \beta+569 \beta^{2}-239 \beta^{3}\right)\right.} . \\
\left.+b^{8}\left(65-199 \beta+237 \beta^{2}-135 \beta^{3}+36 \beta^{4}\right)-b^{10}\left(11-37 \beta+47 \beta^{2}-25 \beta^{3}+4 \beta^{4}\right)\right]
\end{gathered}
$$

Note that superscript $*$ is used to represent the subgame perfect equilibrium market outcomes. Thus, the output levels of both firms in the equilibrium are given as follows ${ }^{8}$ :

$$
\begin{aligned}
q_{0}^{*}= & (a-m)\left[12-b^{2}(5-9 \beta)+b^{4}(1-\beta)\right] \\
& {\left[24-18 b+b^{3}(14-26 \beta)-b^{6}(1-\beta)^{2}+b^{7}(1-\beta)^{2}\right.} \\
& \frac{\left.-4 b^{2}(5-8 \beta)-b^{5}\left(5-12 \beta+9 \beta^{2}\right)+b^{4}\left(9-10 \beta+13 \beta^{2}\right)\right]}{\left[288-b^{2}(576-636 \beta)+b^{12}(1-\beta)^{3}+b^{4}\left(490-950 \beta+568 \beta^{2}\right)-b^{6}\left(225-607 \beta+569 \beta^{2}-239 \beta^{3}\right)\right.}, \\
& \left.+b^{8}\left(65-199 \beta+237 \beta^{2}-135 \beta^{3}+36 \beta^{4}\right)-b^{10}\left(11-37 \beta+47 \beta^{2}-25 \beta^{3}+4 \beta^{4}\right)\right] \\
q_{1}^{*}= & (a-m)\left[12-b^{2}(5-9 \beta)+b^{4}(1-\beta)\right]\left(1+b^{2} \beta\right) \\
& \frac{\left[12-2 b(6-\beta)+b^{4}(1-\beta)-b^{5}(1-\beta)-b^{2}(5-9 \beta)+b^{3}\left(5-7 \beta+4 \beta^{2}\right)\right]}{\left[288-b^{2}(576-636 \beta)+b^{12}(1-\beta)^{3}+b^{4}\left(490-950 \beta+568 \beta^{2}\right)-b^{6}\left(225-607 \beta+569 \beta^{2}-239 \beta^{3}\right)\right.} . \\
& \left.+b^{8}\left(65-199 \beta+237 \beta^{2}-135 \beta^{3}+36 \beta^{4}\right)-b^{10}\left(11-37 \beta+47 \beta^{2}-25 \beta^{3}+4 \beta^{4}\right)\right]
\end{aligned}
$$

Hence, from easy calculations, we obtain the following results on the difference between the output and capacity levels of both firms:

$$
\begin{aligned}
& q_{0}^{*}-x_{0}^{*} \\
& =-\frac{(1-b) b(1+b)(a-m)\left[3-b^{2}(1-2 \beta)\right]\left[12-2 b(6-\beta)+b^{4}(1-\beta)-b^{5}(1-\beta)-b^{2}(5-9 \beta)+b^{3}\left(5-7 \beta+4 \beta^{2}\right)\right]}{\left[288-b^{2}(576-636 \beta)+b^{12}(1-\beta)^{3}+b^{4}\left(490-950 \beta+568 \beta^{2}\right)-b^{6}\left(225-607 \beta+569 \beta^{2}-239 \beta^{3}\right)\right.} \\
& \left.\quad+b^{8}\left(65-199 \beta+237 \beta^{2}-135 \beta^{3}+36 \beta^{4}\right)-b^{10}\left(11-37 \beta+47 \beta^{2}-25 \beta^{3}+4 \beta^{4}\right)\right] \\
& <0 \quad \forall b \in(0,1), \text { and } \forall \in \beta \in[0,1),
\end{aligned}
$$

${ }^{8}$ The equilibrium price levels of both the public firm and the private firm are given in the Appendix. 


$$
\begin{aligned}
q_{1}^{*}-x_{1}^{*}= & -(1-b) b(a-m)\left[1+b^{2}(1+2 \beta)\right] \\
& \frac{+24 \beta-2 b^{2}(8-15 \beta) \beta-b^{6}(1-\beta)^{2} \beta-6 b(2+\beta)}{\left.+b^{4} \beta\left(5-12 \beta+9 \beta^{2}\right)-b^{5}\left(1-\beta^{2}\right)+b^{3}\left(5-6 \beta-5 \beta^{2}\right)\right]} \\
& {\left[288-b^{2}(576-636 \beta)+b^{12}(1-\beta)^{3}+b^{4}\left(490-950 \beta+568 \beta^{2}\right)-b^{6}\left(225-607 \beta+569 \beta^{2}-239 \beta^{3}\right)\right.} \\
& \left.+b^{8}\left(65-199 \beta+237 \beta^{2}-135 \beta^{3}+36 \beta^{4}\right)-b^{10}\left(11-37 \beta+47 \beta^{2}-25 \beta^{3}+4 \beta^{4}\right)\right]
\end{aligned}
$$

Thus, different from the analysis of quantity-setting competition in Nakamura and Saito [19], the difference between the output and capacity levels of the public firm does not depend on both the degree of importance of firm 1 's relative performance and the degree of product differentiation'. In contrast, the difference between firm 1's output and capacity levels strictly depends on both the degree of product differentiation and the degree of importance of its relative performance. From these facts, we obtain the next proposition on the difference between the output and capacity levels of firms 0 and 1 .

Proposition 1 Public firm 0 chooses over-capacity, $q_{0}^{*}<x_{0}^{*}$, for any $b \in(0,1)$ and $\beta \in[0,1)$. In contrast, the difference between private firm 1's output and capacity levels strictly depends on both the degree of product differentiation and the degree of importance of its relative performance. More precisely, private firm 1 selects over-capacity, $q_{1}^{*}<x_{1}^{*}$, if the degree of importance of its relative performance $\beta$ is high relative to the degree of product differentiation $b$, whereas it selects under-capacity, $q_{1}^{*}>x_{1}^{*}$, otherwise. Moreover, the area in the $(b, \beta)$-plane wherein the private firm 1 selects under-

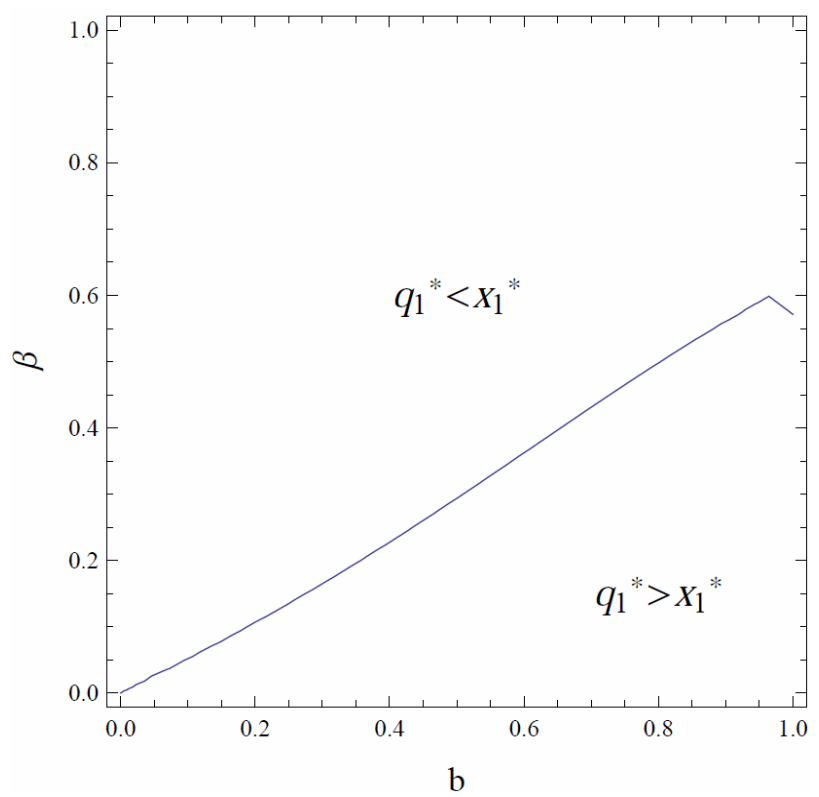

Figure 1. Difference between firm 1's output and capacity levels in the equilibrium. capacity becomes wider as the value of the degree of product differentiation $b$ increases.

Propostition 1 gives that public firm 0 chooses overcapacity for any degree of product differentiation and any degree of importance of the private firm's relative performance. The intuition behind this result is similar to that presented in Bárcena-Ruiz and Garzón [7]. From Equation (2), when the goods produced by both the public firm and the private firm are substitutable, the price level of the private firm is negatively associated with the capacity level of the public firm for an arbitrary value of the degree of importance of the private firm's relative performance. As explained in Bárcena-Ruiz and Garzón [7], the public firm attempts to enhance social welfare by increasing its capacity level and consequently by inducing aggressive behavior from the private firm in the market.

In contrast, in Proposition 1, it is also stated that the difference between the private firm's output and capacity levels strictly depends on both the degree of product differentiation and the degree of importance of the private firm's relative performance, as described in Figure 1. As indicated in Nakamura and Saito [19], the firm whose objective function is its relative profit behaves comparatively aggressively in the market, and thus the private firm sets a lower price level and a higher output level when it is a relative-profit-maximizer than when it is only a sole profit-maximizer ${ }^{10}$. Therefore, when the degree of importance of the private firm's relative performance is high relative to the degree of product differentiation, the private firm strategically tends to choose over-capacity even if the goods of the public firm and the

\footnotetext{
${ }^{9}$ In Nakamura and Saito [19], when the public firm and the private firm engage in a quantity-setting competition, it is shown that when both the degree of importance of the private firm's relative performance and the degree of product differentiation are sufficiently high, the public firm can choose over-capacity, whereas it chooses under-capacity otherwise.

${ }^{10}$ As indicated in Matsumura and Matsushima [20], under a quantitysetting competition with homogeneous goods, in a private oligopolistic market, it is well-known that firms set their output levels such that the market price coincides with their marginal costs when $\beta=1$. Therefore, in a quantity-setting homogeneous goods market, when $\beta=1$, the equilibrium market outcomes coincide with the perfectly competitive market outcomes. Moreover, as indicated in Matsumura and Okamura [18] and Nakamura and Saito [19], even under product differentiation in a mixed duopolistic market, an increase in the value of $\beta$ indicates more intense competition, since the equilibrium price level decreases in $\beta$.
} 
private firm are substitutable, which is strikingly different from the result shown in the existing literature on capacity choice in a price-setting mixed duopoly. Otherwise, that is, when the degree of product differentiation is high relative to the degree of importance of the private firm's relative performance, the private firm strategically chooses under-capacity. The intuition behind this result is explained by the influence of the parameter of the degree of product differentiation on the difference between the private firm's output and capacity levels. From Equation (1), the price level of the public firm is negatively associated with the capacity level of the private firm for any value of the degree of production differentiation $b$ and any value of the degree of importance of the private firm's relative performance $\beta$. Therefore, the private firm sets a low capacity level comparative to its output level in order to enlarge its market share by decreasing its capacity level, and consequently by decreasing the output level of the public firm.

Finally, given a degree of importance of the private firm's relative performance, when the degree of product differentiation $b$ increases, the private firm strategically tends to choose under-capacity, since the effect of $b$ on the difference between the private firm's output and capacity levels is sufficiently strong. Therefore, as the degree of product differentiation $b$ increases, it is likely that the area in the $(b, \beta)$-plane wherein the difference between the private firm's output and capacity levels is positive, becomes wider.

\section{Conclusions}

This paper investigated the difference between the output and capacity levels of both the public firm and the private firm in a price-setting mixed duopoly with differentiated goods, in particular when the objective function of the private firm is its relative profit. In this paper, we showed that the public firm chooses over-capacity irrespective of both the degree of product differentiation and the degree of importance of its relative performance, whereas the difference between the output and capacity levels of the private firm strictly depends on both the degree of product differentiation and the degree of importance of its relative performance.

The result on the difference between the output and capacity levels of the public firm is explained by the same intuition as that presented in the case wherein the private firm is only a profit-maximizer, while the result that the private firm strategically chooses over-capacity

\footnotetext{
${ }^{11}$ As stated in Section 3, the influence of the degree of importance of the private firm's relative performance $\beta$ on the difference between its output and capacity levels is completely opposite from that of the degree of product differentiation $b$. Therefore, the private firm can strategically set over-capacity when the value of $\beta$ is high relative to that of $b$ even if the relation between the products of the public firm and the private firm is restricted to be substitutable.
}

is explained by the effect of the degree of importance of its relative performance, which has not been taken into consideration in the existing literature in this field. More precisely, even under a product-differentiation setting in a mixed duopoly, the private firm aggressively behaves in the market when it is a relative-profit-maximizer rather than when it is only a profit-maximizer. Thus, in particular, when the degree of importance of the private firm's relative performance is highly relative to the degree of product differentiation, the difference between its output and capacity levels can be negative ${ }^{11}$. Therefore, similar to a quantity-setting competition with differentiated goods, in a price-setting mixed duopolistic market, whether the private firm chooses over-capacity or under-capacity depends not only on the relation between both firms' goods but also on the degree of importance of its relative performance.

\section{REFERENCES}

[1] A. Nishimori and H. Ogawa, "Do Firms Always Choose Excess Capacity?" Economics Bulletin, Vol. 12, No. 2, 2004, pp. 1-7.

[2] Y. Horiba and S. Tsutsui, "International Duopoly, Tariff Policies and the Case of Free Trade," Japanese Economic Review, Vol. 51, No. 2, 2000, pp. 207-220. doi: $10.1111 / 1468-5876.00147$

[3] A. Dixit, "The Role of Investment in Entry Deterrence," Economic Journal, Vol. 90, No. 357, 1980, pp. 95-106. doi: $10.2307 / 2231658$

[4] J. A. Brander and B. J. Spencer, "Strategic Commitment with R\&D: The Symmetric Case," Bell Journal of Economics, Vol. 14, No. 1, 1983, pp. 225-235. doi: $10.2307 / 3003549$

[5] M. Wen and D. Sasaki, "Would Excess Capacity in Public Firm Be Socially Optimal?" Economic Record, Vol. 77, No. 238, 2001, pp. 283-290. doi:10.1111/1475-4932.t01-1-00023

[6] H. Ogawa, "Capacity Choice in the Mixed Duopoly with Product Differentiation," Economics Bulletin, Vol. 12, No. 8, 2006, pp. 1-6.

[7] J. C. Bárcena-Ruiz and M. B. Garzón, "Capacity Choice in a Mixed Duopoly under Price Competition," Economics Bulletin, Vol. 12, No. 26, 2007, pp. 1-7.

[8] Y. Lu and S. Poddar, "Mixed Oligopoly and the Choice of Capacity," Research in Economics, Vol. 59, No. 4, 2005, pp. 365-374. doi:10.1016/j.rie.2005.09.004

[9] Y. Lu and S. Poddar, "The Choice of Capacity in Mixed Duopoly under Demand Uncertainty," Manchester School, Vol. 74, 2006, pp. 266-272. doi:10.1111/j.1467-9957.2006.00492.x

[10] Y. Tomaru, Y. Nakamura and M. Saito, "Capacity Choice in a Mixed Duopoly with Managerial Delegation," Economics Bulletin, Vol. 29, No. 3, 2009, pp. 1904-1924.

[11] C. Fershtman and K. Judd, "Equilibrium Incentives in Oligopoly," American Economic Review, Vol. 77, No. 5, 1987, pp. 927-940. 
[12] S. D. Sklivas, "The Strategic Choice of Management Incentives," RAND Journal of Economics, Vol. 18, No. 3, 1987, pp. 452-458. doi:10.2307/2555609

[13] J. Vickers, "Delagation and the Theory of the Firm," Economic Journal, Vol. 95, 1985, pp. 138-147. doi: $10.2307 / 2232877$

[14] Y. Lu and S. Poddar, "Endogenous Timing in a Mixed Duopoly and Private Duopoly - 'Capacity-Then-Quantity' Game," Australian Economic Papers, Vol. 48, No. 2, 2009, pp. 138-150. doi:10.1111/j.1467-8454.2009.00369.x

[15] J. C. Bárcena-Ruiz and M. B. Garzón, "Endogenous Timing in a Mixed Duopoly with Capacity Choice," Manchester School, Vol. 78, No. 2, 2010, pp. 93-109. doi:10.1111/j.1467-9957.2009.02137.x

[16] N. Singh and X. Vives, "Price and Quantity Competition in a Differentiated Duopoly," RAND Journal of Economics, Vol. 15, No. 4, 1984, pp. 546-554.

[17] X. Vives, "Commitment, Flexibility, and Market Outcomes," International Journal of Industrial Organization, Vol. 4, No. 2, 1986, pp. 217-229. doi:10.1016/0167-7187(86)90032-9

[18] T. Matsumura and M. Okamura, "Competition and Privatization Policy: The Relative Performance Approach," 2010.

[19] Y. Nakamura and M. Saito, "Capacity Choice in a Mixed Duopoly: The Relative Performance Approach,” 2013.

[20] T. Matsumura and N. Matsushima, "Competitiveness and Stability of Collusive Behavior," Bulletin of Economic Research, Vol. 64, No. s1, 2012, pp. s22-s31. doi:10.1111/j.1467-8586.2012.00439.x

[21] L. Kockesen, E. A. Ok and R. Sethi, "The Strategic Advantage of Negatively Interdependent Preferences," Journal of Economic Theory, Vol. 92, No. 2, 2000, pp. 274299. doi:10.1006/jeth.1999.2587

[22] S. W. Joe, "Strategic Managerial Incentive Compensation in Japan: Relative Performance Evaluation and Product Market Collusion," Review of Economics and Statistics, Vol. 81, No. 2, 1999, pp. 303-313. doi:10.1162/003465399558094

\section{Appendix}




\section{Each Firm's Equilibrium Price Level}

$$
\begin{aligned}
& p_{0}^{*}=\frac{a b\left(1-b^{2}\right) A+m B}{\left[288-b^{2}(576-636 \beta)+b^{12}(1-\beta)^{3}+b^{4}\left(490-950 \beta+568 \beta^{2}\right)-b^{6}\left(225-607 \beta+569 \beta^{2}-239 \beta^{3}\right)\right.}, \\
&\left.+b^{8}\left(65-199 \beta+237 \beta^{2}-135 \beta^{3}+36 \beta^{4}\right)-b^{10}\left(11-37 \beta+47 \beta^{2}-25 \beta^{3}+4 \beta^{4}\right)\right] \\
& p_{1}^{*}=\frac{a(1-b) C+m D}{\left[288-b^{2}(576-636 \beta)+b^{12}(1-\beta)^{3}+b^{4}\left(490-950 \beta+568 \beta^{2}\right)-b^{6}\left(225-607 \beta+569 \beta^{2}-239 \beta^{3}\right)\right.}, \\
&\left.+b^{8}\left(65-199 \beta+237 \beta^{2}-135 \beta^{3}+36 \beta^{4}\right)-b^{10}\left(11-37 \beta+47 \beta^{2}-25 \beta^{3}+4 \beta^{4}\right)\right] \\
& \quad A=72-b^{2}(66-114 \beta)-12 b(6-\beta)+b^{8}(1-\beta)^{2}-b^{9}(1-\beta)^{2} \\
& \quad \text { where }+4 b^{7}(2-\beta)(1-\beta)^{2}+b^{4}\left(33-70 \beta+45 \beta^{2}\right)-2 b^{6}\left(4-11 \beta+7 \beta^{2}\right) \\
& \quad+2 b^{3}\left(33-54 \beta+17 \beta^{2}\right)-b^{5}\left(33-66 \beta+49 \beta^{2}-20 \beta^{3}\right) \\
& B=288-72 b-b^{2}(504-624 \beta)+b^{11}(1-\beta)^{2}-b^{12}(1-\beta)^{2} \beta \\
&+ 6 b^{3}(23-19 \beta)+b^{4}\left(352-830 \beta+534 \beta^{2}\right)+b^{7}\left(41-92 \beta+59 \beta^{2}\right) \\
&- 3 b^{9}\left(3-8 \beta+5 \beta^{2}\right)-b^{5}\left(99-184 \beta+45 \beta^{2}\right)-b^{6}\left(126-433 \beta+486 \beta^{2}-219 \beta^{3}\right) \\
&+ b^{8}\left(24-113 \beta+172 \beta^{2}-111 \beta^{3}+36 \beta^{4}\right)-b^{10}\left(2-15 \beta+30 \beta^{2}-21 \beta^{3}+4 \beta^{4}\right) \\
& C=144-b^{2}(240-252 \beta)-b^{10}(1-\beta)^{2}-24 b \beta+2 b^{9}(1-\beta)^{2} \beta(1+2 \beta) \\
&-2 b^{3} \beta(1+45 \beta)+b^{4}\left(183-244 \beta+181 \beta^{2}\right)+2 b^{5} \beta\left(7+12 \beta-51 \beta^{2}\right) \\
&-b^{6}\left(67-126 \beta+71 \beta^{2}-56 \beta^{3}\right)+b^{8}\left(13-24 \beta+19 \beta^{2}-8 \beta^{3}\right) \\
&-2 b^{7} \beta\left(3-\beta-14 \beta^{2}+18 \beta^{3}\right) \\
& D= 144-b^{2}(336-360 \beta)-b^{11}(1-\beta)^{2}-b^{12}(1-\beta)^{3}+24 b(6+\beta) \\
&-b^{4}\left(307-708 \beta+297 \beta^{2}\right)-b^{3}\left(240-254 \beta-90 \beta^{2}\right) \\
&-b^{6}\left(158-495 \beta+474 \beta^{2}-81 \beta^{3}\right)-b^{10}\left(10-37 \beta+46 \beta^{2}-19 \beta^{3}\right) \\
&+b^{8}\left(52-181 \beta+220 \beta^{2}-99 \beta^{3}\right)+b^{5}\left(183-258 \beta+157 \beta^{2}+102 \beta^{3}\right) \\
&-b^{7}\left(67-132 \beta+73 \beta^{2}-28 \beta^{3}-36 \beta^{4}\right)+b^{9}\left(13-26 \beta+19 \beta^{2}-2 \beta^{3}-4 \beta^{4}\right)
\end{aligned}
$$

